Article

\title{
Emotional Dimensions in Integrated Care for People with Multiple Complex Problems
}

\author{
Anneli Hujala ${ }^{1, *}$ and Erja Oksman ${ }^{2}$ \\ 1 Department of Health and Social Management, University of Eastern Finland, FI-70211 Kuopio, Finland \\ 2 Päijät-Häme Welfare Group, FI-15850 Lahti, Finland; erja.oksman@phhyky.fi \\ * Correspondence: anneli.hujala@uef.fi
}

Received: 27 August 2018; Accepted: 4 October 2018; Published: 8 October 2018

\begin{abstract}
Cross-boundary collaboration, both multiprofessional and interorganizational, is needed when providing integrated care for people with multiple problems, who need services at the same time from diverse care providers. Multiple problems of clients also pose extra challenges for interaction between care professionals and clients. Emotional dynamics are always present in everyday interaction between human beings, but seldom explicitly addressed in research on integrated care. The aim of this reflective paper is to illustrate the emotional dimensions of integrated care in light of the experiences of care professionals in the context of care for people with multiple complex problems. The paper draws on a Finnish study on integrated care reflecting its findings from the perspective of emotional labor. The difficult life situations of people with multiple complex problems form an emotional burden, which is mirrored in the interaction between clients and professionals and affects relational dynamics among professionals. Professionals' fear of emotions and the different 'feeling rules' of care professions and sectors pose extra challenges to professionals' collaboration in this emotionally loaded context. Alongside the structural and functional aspects of integrated care, it is important that emotions embedded in everyday cross-boundary collaboration are recognized and taken into account in order to ensure the success of integrated care.
\end{abstract}

Keywords: integrated care; emotions; emotional labor; cross-boundary collaboration; care professional; patient; client; people with multiple complex problems; health and social care

\section{Introduction}

Integrated care is a concept used extensively to refer to advanced collaboration in the context of health and social care. To put it simply, integration means 'bringing together different actors or activities' (Axelsson and Axelsson 2009). Cross-sectoral collaboration, referring here to both multi-professional and inter-organizational collaboration of professionals and collaboration between clients and professionals, is needed to make care services for people more co-ordinated, flexible and continuous within the care systems, in order to produce better care for people. Person-centeredness is at the center of integrated care (World Health Organization 2016) and a holistic professional-client relationship forms a salient basis for cross-boundary collaboration. Multiprofessional refers here to collaboration between professionals (doctors, nurses, social workers) and interorganizational to collaboration over sectoral boundaries (primary health care, specialized health care, and social care).

Integrated care is expected to be of particular benefit for people with multiple complex health and social care problems who need services from several care providers in both health and social care (Goodwin 2015; Rijken et al. 2017). These people, from a collaboration perspective also called 'shared clients' (Oksman 2017), consist of somewhat different groups, such as those with multimorbidity, older persons regularly needing acute health services for several reasons, families with children who have special problems, drug users, young people or adults who suffer from mental problems. What these 
client groups have in common is that they need services from several care providers at the same time: from hospitals, from health centers or general practitioners in primary health care and also from social care. The existing disease-based and fragmented care systems do not meet the needs of people with multiple complex problems (Hujala et al. 2017). Collaboration between clients and professionals and among various professionals and between the sectors of care-specialized care, primary care and social care-is crucial.

Person-centered integrated care has been offered as a solution to solve the problems described above regarding care for people with multiple complex problems (Ahgren 2012; Van der Heide et al. 2018). This reflective paper draws on experiences and insights from a Finnish study addressing care professionals developing integrated care pathways for 'shared clients'. The emotional and other relational dynamics that the study participants highlighted in relation to these clients inspired us to take a closer look at the emotional side of integrated care and to consider if an approach addressing emotions could give any added value to the concept and approach of integrated care.

Collaboration among care professionals has been studied extensively (Cameron et al. 2014; D'Amour et al. 2008; Schepman et al. 2015), often specifically addressing the barriers and difficulties of multi-professional collaboration (see Axelsson and Axelsson 2009). Previous research has shown that successful collaboration between professionals requires a shared goal, commitment, trust and respect between the participants (e.g., Willumsen et al. 2012; see also Schruijer 2008). These issues may sound quite familiar, but it is not always so easy to realize this ideal in practice. The reasons why cross-boundary collaboration is so challenging may be better understood by also paying attention to emotional tensions, which tend to pervade all interaction between human beings.

In the context of integrated care, challenges related to interaction between human beings, such as emotional dynamics, are seldom explicitly addressed. This is not exceptional given that emotions have long been 'the neglected side' of organizational research in general (Fox and Spector 2002). At least, integrated care is most often described as a phenomenon taking place at system, organizational, professional and clinical levels, including functional and normative dimensions (Valentijn et al. 2013). Although numerous approaches and models of integrated care are available (see, e.g., World Health Organization 2016), the focus of research on integrated care is often on the structures, processes and tools of integration. Processes of integrated care refer to collaborative processes, but the main focus of integrated care is functional addressing the concrete ways in which collaboration should be organized and paying less attention to the human side of integrated care. Normative integration, which perhaps has the closest relationship to emotional dimensions, does indeed address the different values and cultures of professionals. These aspects have recently been emphasized by an approach highlighting value-based integration (see Minkman 2016), aiming at a better understanding of the values underpinning integrated care. In addition, person-centeredness has become a core aim of integrated care, emphasizing the importance of taking into account patients' needs and wishes and focusing more on person-relevant outcomes of integrated care (Van der Heide et al. 2018).

However, in spite of the recent diversification of the perspectives on integrated care we venture to claim that mainstream research and practice focus on the conventional points of views of rationality, where human beings tend to be rendered as rational actors in a technical and practical framework. Less attention is paid to the social, emotional and affective dimensions of integrated care. As in planning processes in general, these may even be considered irrational and irrelevant (see Osborne and Grant-Smith 2015). Emotional and other relational dynamics are present in particular when implementing integrated care, because ultimate implementation takes place at grass-root level in interaction between human beings.

As a phenomenon, emotions can be approached from a variety of perspectives. Traditionally emotions have been considered to be individual and internal phenomena (Osborne and Grant-Smith 2015). Psychodynamics emphasize the nonconscious nature of emotions at individual level; systems psychodynamics (developed by the Tavistock Institute of Human Relations) link nonconsciouos dynamics with organizational structures and see that routines and practices can serve as a social 
defence to manage the emotions of organizational members (Pratt and Crosina 2016). According to the constructionist approach, emotions do not exist inside us; they are not only an individual or internal phenomenon, but emerge from social interaction (Harré 1986; see also Gergen 1999). Our emotions are very closely connected to our relationships to other people (Burkitt 2014, p. 2); Brotheridge and Lee (2008, p. 109) claim that emotions are 'at the heart of all working relationships'. Further, emotions can be considered as emotional intelligence (e.g., Morrison 2007) or emotional competencies (e.g., Kinman and Grant 2011).

In this paper, we apply a broad understanding of emotions, recognizing both the individual and social dimensions related to them. One potential option to approach theoretically the presence of emotions in integrated care is the concept of emotional labor (Hochschild 1983; see also Zapf 2002; Zapf and Holz 2006). The concept was originally introduced by Arlie Hochschild in 1983 and has since also been applied in the field of health and social care (Mann 2005), especially in nursing (e.g., Gray 2009; Hunter and Smith 2007). Hochschild's 'sociology of emotions' reveals the taken-for-granted nature of interaction between people. It pays attention to what people feel, how they make sense of their feelings and how people have to regulate and manage their feelings not only in their individual lives (emotion work) but also at work (emotional labor) (Hochschild 1983; Garey and Hansen 2011).

In the emotional labor approach (Hochschild 1983), the client-employee relationship is emphasized, which matches well with the nature of person-centered integrated care. In this paper we do not focus so much on the ways care professionals display the appropriate feelings in given (face-to-face) situations with clients. Instead, the focus here is on the assumption that feelings related to the multiple complex problems of clients affect professionals' actions in any case-whether they are aware of them or not-in all their doings, not only in interaction with clients but also with other professionals. In emotional labor research, the original concepts of surface acting (faking emotions) and deep acting (trying to feel actual emotions required in the situation) have been complemented by a third form of emotional labor, natural and genuine emotional labor (Humphrey et al. 2015), which we think suits well in the context of care. A fruitful concept matching with care for people with multiple complex problems is emotional dissonance. Further, so-called feeling rules (display rules), i.e., organizational norms of feeling (Hochschild 1983; see also Diefendorff et al. 2011; Humphrey et al. 2015; Grandey and Melloy 2017) link the approach interestingly to cross-boundary collaboration in the context of shared clients.

This reflective paper is based on a Finnish study on integrated care. The aim here is to describe and illustrate the emotional and other relational dimensions of integrated care in light of the experiences of care professionals in the context of care for people with multiple complex problems. We hope that the insights presented here will raise further discussion on whether it is worth addressing 'the affective turn' (Burkitt 2014; Greco and Stenner 2008) and emotional dimensions more profoundly and in more detail in future research on integrated care.

\section{Materials and Methods}

The empirical material reflected here comes from a Finnish research project, Onnistu sote-integraatiossa/ Successful Integration of Health and Social Care (2016-2018), funded by the Finnish Foundation for Municipal Development (KAKS). The study was conducted in close collaboration with Parempi Arki/Better Everyday Life (BEL) development project (2015-2017), funded by the Ministry of Social Affairs and Health (Finland). The aim of the BEL development project was to support clients with multiple problems in everyday life by developing a person-centered and integrated care approach including services in both health care and social care. The overall aim of the research project was to add to the understanding of the prerequisites for successful integration. The BEL project was a pilot project addressing implementation of integrated care, connected to Finland's national reform aiming at the complete integration of health and social care in 2021.

In total, 250 care professionals from primary health care, specialized health care, social care, and the education sector were involved in the BEL development project. These same professionals 
were also the participants in the research project. The study participants were professionals working in the field of health and social care: nurses, doctors, social workers, therapists, teachers etc. The BEL project was an intervention project in which the professionals from different sectors (primary health care, specialized health care, social care and the education sector) and organizations (health centers, hospitals, social care organizations, schools) were joined together into 37 local cross-boundary development teams. The aim of these teams was to develop integrated care pathways for clients with multiple complex problems and multiple care needs-pathways linking care professionals from different organizations and different sectors to work together for the good of the people with multiple problems. Each team developed care for a chosen target group, for example for older persons regularly needing health services or for families with children who have special problems. The work of the BEL teams was supported by project coaches and through seminars (applying the Breakthrough method and other Leanmethods, see Bhat et al. 2014). Theoretically the development work drew on the extended Chronic Care Model (Barr et al. 2003).

The close collaboration between the research project and the development project enabled access to all materials produced by the BEL development project. The researcher (first author) was present in the seminars and workshops of the BEL project and the project manager of it (second author) also worked as a researcher, taking part in some of the interviews and in the data analysis. Together with the professionals involved in the development project, these arrangements enabled a fruitful dialogue between research and practice.

This reflective paper draws on the overall material and findings of both projects, in particular on the following data: (1) Lean-based Fishbone problem analysis (see Bhat et al. 2014) regarding clients with multiple complex problems, done by 21 BEL project teams (about 100 professionals). In these fishbone analyses the professionals analyzed the critical points in providing care for people with multiple complex problems. The outputs of the teams' analyses were transcribed and Atlas.ti software was used for preliminary thematic analysis of the fishbone problem analysis; (2) Research interviews with professionals and managers. Three cross-boundary BEL project teams were interviewed. Altogether, 14 care professionals (nurses, social workers, physiotherapists and doctors) from primary health care, social care and specialized health care participated these group interviews. In addition, individual interviews with nine managers connected to the BEL project, representing primary and specialized health care and social care were interviewed. Interviews were conducted by the authors of this paper (the researcher and the BEL project manager).

The interview themes concerned the professionals' experiences with clients with multiple complex problems, the challenges in providing and developing care for them, experiences of cross-boundary collaboration related to these clients, expectations of the collaboration outcomes, and management issues related to cross-boundary collaboration. The research material was analyzed by means of inductive content analysis and the original findings are presented in the research report (Hujala and Lammintakanen 2018). For the purposes of this reflective paper, the findings of the original analyses are used selectively to highlight the emotional and other relational aspects of the research material. The themes described below (1) emotional burden; (2) professionals' fear of emotions and (3) 'emotional territories' are based on the holistic reflection of the whole research material and illustrated here by purposefully selected quotations from the data.

\section{Findings}

\subsection{Emotional Burden}

The general and initial orientation of the whole research project was quite conventionally to address the prerequisites and challenges for a successful integration of care for people with multiple complex problems. During the development project and the related research process it became obvious-somewhat unexpectedly in a quite rational and functional framework of integrated care-how strongly care professional related emotions to integrated care for people with multiple 
complex problems. The findings of the study showed that the emotional burden of multiple complex health and social problems affects not only clients, but also the care professionals who deal with these people in their work.

The lives of people with multiple complex problems are often very difficult for themselves and for their next-of-kin. The existing disease-based and fragmented care systems do not meet the needs of these clients. This incompatibility causes clients serious difficulties: physical and/or mental illnesses, social and other related problems are a burden as such, and problems experienced with the health and social care system are felt to cause additional burden. In the following, we first describe the experiences of professionals, how and why they often felt these clients to be a burden and the effects they felt this burden to cause - not only to clients, but also to the professionals themselves. ${ }^{1}$

Both in the fishbone analyses and in the interviews, the professionals reported that clients with multiple problems get lost, become exhausted and wear themselves out in poorly coordinated service systems. In the fragmented care systems, clients are sent from one professional to another. Nobody is responsible for the coordination of their care, and clients have to repeat their problems over and over again to new professionals, who are not aware of a client's medical history.

He had been sent from one place to another ... and now he is a client in very many places $\ldots$ and the process continues and continues ... it wears out the resources of the client and professionals are also coming to feel the lack of resources. (Care professional Px, not identified from the recording)

The professionals also recognized that people with multiple needs very often feel shame because of their problems. They are ashamed because they feel they lack the ability to cope with their lives. Shame is connected with a fear of being doomed, looked down on or being stigmatized by professionals. It is understandable that it is not easy to discuss difficult or sensitive problems with outsiders. Even asking for help occasionally may be felt to be difficult and degrading. The burden of such feelings multiplies when people have to confront these problems for a long time and explain them over and over again to new care professionals.

All this also leaves professionals feeling frustrated, inadequate and helpless. When clients' problems are complex, especially because this situation goes on and on, an individual professional feels that $\mathrm{s} /$ he just does not have solutions for the situation.

$\ldots$ and the feeling of frustration for doctors and nurses ... again ... that very same client is here again and we cannot offer her anything and we are not able to help her. (Manager M4)

Then both parties are exhausted and tired and do not know what to do. (Care professional Px, not identified from the recording)

Alongside the picture of the client who is worn out and ashamed about her or his situation, professionals also outlined another kind of image of this client group. They recounted that sometimes clients with multiple problems are evasive and do not tell about their actual problems, they downplay or deny the problem or the real reason behind the problem. Sometimes clients seem to tell a different version to different professionals.

... the client ... sugar-coats the truth or does not tell everything ... it is terribly difficult to really help that kind of client. (Care professional P2)

... The client is able to play any role whatsoever, if s/he wants to do so. (Care professional P3)

1 The experiences of the clients interviewed in the study are described in the original research report (Hujala and Lammintakanen 2018). 
Professionals even spoke about clients as 'exploiters' of the system. Clients may require services, but they do not want to commit themselves to the care they are provided. They are passive, do not keep appointments with professionals and contribute nothing to their self-management. Some clients appeared to professionals as manipulators, who have endless needs. The professionals reported that nothing is enough for such clients.

... then we have this extreme, we have the clients who want everything. And they, they are ready to take everything and they demand everything, and nothing is enough for them. It is that kind of extreme, we have that kind of 'slough' there, that we have to restrict [giving services] ... (Care professional P2)

Emotional labor (emotional work) (Hochschild 1983) applied to this context means that care professionals have to be sensitive to clients' emotional burden and at the same time regulate their-often contradictory-feelings and emotions which arise when they confront clients with continuous complex problems. Feeling empathy and feeling compassion were examples of positive emotions, frustration and exhaustion of negative ones. In addition, in particular the 'exploiters' or 'manipulators' evoked quite extreme feelings such as mistrust, annoyance, cynicism and even anger. The findings of the study suggested that this kind of 'emotional dissonance', conflict between expected and experienced emotions, is not restricted to single face-to-face encounters, but the emotional burden may become a permanent state of mind. This not only results in a poorer quality of care for clients but causes stress and affects professionals' well-being; an impact of emotional labor identified extensively in previous research (see e.g., Zapf and Holz 2006).

\subsection{Pandora's Box: Professionals' Fear of Emotions}

In caring for people with multiple complex problems, one of the critical challenges for professionals is to identify 'shared' clients needing help and support from several care providers and therefore likely to benefit from cross-boundary collaboration among professionals. The professionals emphasized that even if they see that a client seems to have a problem which would require involving other professionals to be solved, it is not easy for the professional to bring the difficult issues to the fore if the client herself/himself is not willing (or is afraid) to talk about them. The fear of emotions creates a barrier between a professional and a client. The professionals described these encounters, for example, as follows.

We do not have the courage and we don't have ways to confront a person, if s/he seems to have a social problem, which is behind everything else. There may be 50 visits [to a doctor or a professional] just because the real reason is loneliness. (Care professional P3)

A lack of time and lack of the 'right' questions are not the only reasons to pass on this kind of situation. One of the professionals interviewed described how she feels when seeing a client in this kind of situation:

It is partly connected to it, that I think that I have only $20 \mathrm{~min}$ time [for the client]. What if s/he says something that I should really intervene in? And I do not have time now, because the next patient is already waiting at the door. So how could I do it in a smart way, so that somebody else could talk with her/him later, or call her/him, or something. (Care professional P3)

Thus, the fear of an emotional reaction inhibits the courage to ask the client about the underlying, wider problems. According to the interviewees, a professional may be afraid that the whole situation will break open. It is worth noting, that the professional is not only worried about the client's emotional reaction, but also about his or her own emotional reaction.

... [A] doctor or a nurse working in a practice does not dare to ask-because $\mathrm{s} / \mathrm{he}$ is afraid that the issue is so sensitive, that the emotional reaction may be anything-either the client's or your own reaction. (Care professional P5) 
The BEL project manager confirmed how it became quite clear during the BEL project that even though professionals identify a client with multiple problems, they may avoid asking about those problems.

... [W] do know the people who traipse to the health center again and again. In a way, we are afraid of opening Pandora's box with the client, because there is no way to go forward. (The BEL project manager in a team interview)

The problem of Pandora's box concerns not only health care professionals and their concerns about patients' social problems. The interviewees explained that also social work professionals, too, may sometimes be too cautious to address 'deeper' problems of clients. They cited an example of a client who comes to see a social worker because of financial problems. It may take time and several visits before both parties are ready to say the underlying reason aloud, which may be, for example, use of alcohol or drugs. The problem of avoiding problematic issues is also recognized in the context of supervising care professionals. Revell and Burton (2016) emphasize the importance of supervision for social workers who confront significant emotional burden in their work, for example in child protection practice. Revell and Burton (Revell and Burton 2016, p. 1596) state, however, that in the same way as professionals also their supervisors may likewise fail to ask about emotionally difficult issues, for fear that they may raise too heavy concerns for discussion.

Difficult matters are tricky to bring out into the open: a professional may doubt his or her own ability to confront the problem. Avoiding an issue is easier, and sending the client to another professional may be a solution-and for the client the vicious circle continues. Integrated care-fixed procedures for multiprofessional collaboration-could be a solution: rather than choosing to avoid emotions by referral of clients, professionals could share the emotional burden by facing the client together.

Professionals may thus lack the courage to ask what is really the matter with the client. However, in the encounters there are always two participants. What hinders the client from bringing problems into the open?

... I think that it is partly because patients are also socialized to act like this ... They know the time is limited, you have to get to the most important point ... the issue you think is important from the professional's point of view, and it is obviously diseases. It cannot be that the professional would be interested in ... this kind of a social problem. (Care professional P6)

... [T]he client thinks that this is such a trivial issue, not worth mentioning. Then neither of them says a word about the most important issue. (Care professional P5)

The identification of the underlying problems is thus based on reciprocal behavior. The care professional focuses only on the issue the client raises and what she assumes the client expects. And the client behaves as she supposes the professional expects her to behave. They may be unsure, shy or even feel fear of professionals. Both lack the courage to get to the point and 'Pandora's box' is left unopened. The professionals called this 'half-way interaction': people do not wholly reach the other party in the interaction.

In emotional labor terminology (Hochschild 1983; Grandey and Melloy 2017), instead of so called surface acting (e.g., expressing emotions which are not genuinely felt) or deep acting (e.g., overcoming negative acting, trying to force oneself to feel positive or other appropriate emotions), the fear of emotions resulted in entirely avoiding and ignoring emotions. This is a very interesting point of view from the perspective of integrated care, while in this kind of situation it would be beneficial for all to ask help from other colleagues. As mentioned earlier, the professionals stated that one of the key problems is that clients are sent from one professional to another, which is just the opposite with the goal of integrated care. Here the professionals explicitly addressed emotional aspects as one reason for doing so-because it is easier than confronting the emotions related to problems. During the BEL 
development project, the professionals practiced concrete cross-boundary collaboration with clients in multiparty teams. A widely shared experience was that collaboration is an efficient way to share the emotional burden due to multiproblem clients. Integrated care arrangements should thus involve practices which encourage professionals to collaborate with other professionals and sectors to share the burden resulting from the demands of emotional labor.

\subsection{Emotional Territories?}

Axelsson and Axelsson (2009) use the word 'territoriality' to refer to the problems of cross-boundary collaboration. They claim that not only animals but also human beings tend to defend their 'own areas'; in the case of integrated care for people with multiple complex problems professional (doctor, nurse, social worker) and sectoral (primary care, specialized care and social care) territories.

It is natural that specialization has resulted in boundaries between care professions and sectors. An interesting question here is now, whether (and if so, how) emotions are related to the differences between professions and sectors. Emotional burden due to complexity of client's problems may be shared by collaboration, but it may also cause additional tensions and challenges in the interaction, if the ways of dealing with emotions differ.

The findings of the study reflected here did not directly address emotional differences between the professions and sectors. However, the professionals felt that there is still a clear distinction between the territories of care professions and sectors. Extreme (but quite general) stereotypes and prejudices underlying cross-sectoral collaboration regarding the three sectors persist and were described in the BEL project seminars by professionals as follows: Primary health care thinks it is omnipotent. Specialized health care isolates itself (due its allegedly superior know-how compared to others). The professionals in social care believe they are the only ones who are able to take a holistic view of a client, but at the same time the health sector wonders whether social care is actually needed. A certain kind of territorial defence seems to be embedded in these stereotypical summaries evidenced by the professionals.

The holistic person-centered view of patients and clients is one potential way to approach the 'emotion-related differences' between professions and sectors. Holistic person-centeredness (patient-centeredness, client-centeredness) is a vital part of integrated care (World Health Organization 2016). Further, the emotional dimension is an explicitly stated part of person-centeredness (Scholl et al. 2014; see also Van der Heide et al. 2018). In the integrative model of patient-centeredness by Scholl et al. (2014, p. 5) 'emotional support' is described as part of patient-centeredness as follows: "Recognition of the patient's emotional state and a set of behavior that ensures emotional support for the patient." In addition, the model states other related dimensions such as 'patient as a unique person' and 'patient empowerment' — while also emphasizing the dimensions addressing collaboration between diverse professionals.

According to the professionals interviewed in this study, in the health sector a patient is often still seen as a 'disease' and in the social sector client is seen 'a holistic person'. This (naturally highly simplified) distinction outlined below is mirrored in the stereotypes of doctors and social workers. A nurse working in the primary care reported as follows:

... I am working at a health care center ... and from the perspective of health care, we are there not able to think, or we have not been able to think of a person as a whole ... we take care of the disease, and we take care of that single thing. (Care professional P3)

The same professional described the role of the doctor as follows:

... [W] hen patients come to a health center, or come to see a doctor, very many of them still think ... they regard a doctor as an authority, an awfully big authority. You go as you were going to see the Almighty ... this is what you have picked up at your mother's knee: you have to [have] a fear of the Lord when you go to see a doctor. And you go to get a 
solution to one problem only ... When one goes to social work professional, the attitude is totally different. (Care professional P3)

Another professional confirmed this and claimed that this hierarchical status is maintained by other actors:

... [A]lso when other people, when they look at the doctor, they look upwards. Like nurses, and especially clients. So, the doctor stays up there if everyone looks up to her $/ \mathrm{him}$. (Care professional P5)

A totally different picture of social work and social workers was outlined by two of the managers interviewed in the study. They emphasized the importance of the relationship and a holistic view of a client.

Altogether, about support work and the basic principles of social work: it is still salient here that you [as a client] form a bond with someone [professional]. That you have a care professional with whom you have some kind of a relationship. And that [relationship] opens up the world for collaboration [between a client and professional] or otherwise that world stays closed. (Manager M1)

I would say like this, in a rather caricatured way, that in a way social services start from the holistic wellbeing of human beings. In health care there is more that old thing, that one has a medical problem which has to be solved and got rid and that's it. But this is, I would claim, it has changed and is changing and it has to be changed. But surely it is still like this. (Manager M9)

The differences between health and social sector are not only boundaries, there also seems to be a distinction between specialized health care and primary health care in how to orient toward holistic patient-centeredness, as shown in the following extract.

Whereas we think that it is not the task of the specialized care this continuous life-long support. It has to be built in the primary care, nearer ... where people live. (Manager M7)

The different basic tasks of the sectors are mirrored naturally in the work of professionals. Especially when dealing with people with complex problems, the competencies of a professional may be challenged because they may be required to collaborate with professionals with completely different expertise and from sectors with completely different orientation towards patient-centeredness. In addition, power embedded in diverse sectors and professions is of course present: for example, it may be more difficult for a social worker to get her voice heard in the context of specialized health care. The uneven power relations embedded in the hierarchy and bureaucracy of the health and social system reinforce territorial thinking and increase mutual suspicion (Axelsson and Axelsson 2009).

If we extend the idea of territorial differences and tensions, through holistic patient-centeredness thinking, to emotional orientation, we could perhaps suggest something like 'emotional territories' embedded in other kinds of professional territories. From the point of view of emotional labor (Hochschild 1983), these emotional territories would refer to the different feeling rules (display rules) (Diefendorff et al. 2011; Humphrey et al. 2015) that different care sectors and different care professionals have. Each territory has to defend its own ways of acting, based on their education, role, status, ethical principles etc. on which their professionality in general is based on (Axelsson and Axelsson 2009)-also in an emotional sense. Diefendorff et al. (2011) define emotional display rules as shared norms, or emotion norms, governing the expression and regulation of emotion at work and claim these can differ depending e.g., on occupational requirements. It is quite understandable that these rules or norms vary across different professions, organizations and sectors. The professional hierarchy in health and social care further reasserts these differences. 
For example, although emotion work is generally considered as part of nursing work, in Gray's study (Gray 2009, p. 171) on emotional labor among nurses the respondents felt-in addition to gender stereotypes-that emotions were seen as 'weaknesses' by other staff members, such as senior nurses and doctors. Conventionally, social work in particular is considered to be emotionally demanding work, in which paying attention to emotions is seen as a critical aspect (Morrison 2007). In spite of this, even in social work sharing feelings and asking for help may be seen as a weakness and lack of professional capacity (Revell and Burton 2016, p. 1595). The differences between professions are, however, changing, while patient-centered care is also getting more attention in medicine. Epstein (2000), for example, includes identification and responding to patient's ideas and emotions regarding their illness as an important component of physicians' behavior.

In integrated care, different feeling rules are encountered when professionals representing different sets of feeling rules work together in cross-boundary teams. In the context of people with multiple complex problems, the emotional burden described above constitutes an extra underlying challenge and complicates collaboration among professionals. We may ask if in such a situation a social worker, for example, dares or is otherwise able to act according the feeling rules of her/his own profession or sector, giving that a medical specialist may be socialized to a very different set of rules. Conversely, for a highly specialized doctor it may be against the conventional work role status and role expectations to become involved in emotional issues. Ashforth and Kreiner (2002, p. 230) refer to problems of 'collective face work' and 'emotional comparison', which may also be of relevance in cross-boundary collaboration between professionals in health and social care. Feeling rules related either to professions, organizations or sectors could also be called emotional climates or emotional cultures (see Grandey and Melloy 2017, p. 412) and merit special attention in the context of implementing integrated care.

\section{Discussion}

The aim of this reflective paper was to highlight the presence of emotions in the context of integrated care regarding, in particular, care for people with multiple complex problems. Although we as the authors of this paper are not experts in research on emotions, we hope this contribution could serve to raise more discussion on why-or if-emotional dimensions also deserve more attention regarding integrated care.

This paper was based on a study conducted only in one country, Finland, and elsewhere its findings can only be indicative. In the whole study, a total of 250 care professionals were involved through the workshops and material they produced in the course of a development project, based on close partnership with the research and development project. However, only a limited number of professionals and managers were interviewed. It is also noteworthy that the original aim of the study was concerned with integrated care in general and not specifically emotional aspects.

Nevertheless, the context of the study adds to its value: Finland's extensive national-level reform, which is expected to take place in 2021, is aiming at full integration of both health and social care (Regional Government 2018), which is still quite a rare effort internationally. Because of increasing interest and need to integrate care services in many other European countries as well (Goodwin 2015), experiences of how to combine rational and technical system level integration with the interactive level of human beings may be of interest to a larger audience. We claim specifically that the human side of integrated care should be taken into account when dealing with people whose life situations are complex and whose needs for care services from different care providers are high and complicated.

Based on the study reflected in this paper the following issues were highlighted:

- People with multiple complex problems are a salient and challenging client group in integrated care, and the emotional burden connected to them needs to be taken seriously. The emotional burden affects not only clients themselves but also professionals.

- Care professionals providing integrated care for this client group perform emotional labor: they have to balance with contradictory emotions and cope with emotional dissonance. Fear of 
emotions may result in avoiding confronting clients' problems. By integrated care arrangements, through cross-boundary collaboration, the temptation to just send a complicated client on to the next professional could be avoided.

- Emotional burden may have a negative effect on the wellbeing of professionals, which is an important consideration when aiming at sustainable and effective health and care systems (see Bodenheimer and Sinsky 2014).

- Cross-boundary collaboration among professionals has potential to share the emotional burden. However, the different 'feeling rules' or 'emotional cultures' (Hochschild 1983; Diefendorff et al. 2011) of care professions and sectors may be a challenge to the implementation in practice of integrated care.

To sum up, according to the research findings reflected here, integrated care is not only rational action. As Griffith and Glasby (2015) state, public policies on integrated care focus mainly on structural issues. However, although macro- and meso-level integration form the grounds for cross-boundary collaboration, the ultimate implementation of integration is accomplished at micro level by grassroots actors in interaction between care professionals and clients. There is no need to exaggerate the significance of emotional dimensions of integrated care, but no reason to avoid or neglect them, either. The aim should perhaps be to 'normalize' emotions (Ashforth and Kreiner 2002) and emotion labor (Hochschild 1983) as part of the implementation of integrated care. This means 'making the extraordinary seem ordinary' (Ashforth and Kreiner 2002) so that both the identification and sharing of the emotional burden among care professionals would be an accepted and routine way of working in cross-boundary collaboration. As stated in systems psychodynamics (Pratt and Crosina 2016), organizational structures may be established to protect individuals from emotions; structural arrangements enhancing collaboration may thus also serve as arenas for professionals to share the burden of emotions. In addition, training for professionals in confronting emotional situations and emotional pressures in cross-boundary collaboration is needed (Diefendorff et al. 2011). We believe that the emotional dimensions present in everyday life interactions (Jacobsen 2019; Williams 2001) deserve more attention-hopefully from multidisciplinary perspectives-in the future research of integrated care, in particular in the context of cross-boundary collaboration among care professionals needed by people with multiple complex problems.

Author Contributions: The authors contributed equally to this paper.

Funding: The research project Onnistu sote-integraatiossa (Successful Integration of Health and Social Care) was funded by the Finnish Foundation for Municipal Development (KAKS) and the development project Parempi Arki (Better Everyday Life) by the Ministry of Social Affairs and Health (Finland).

Conflicts of Interest: 'The authors declare no conflicts of interest.

\section{References}

Ahgren, Bengt. 2012. The Art of Integrating Care: Theories Revisited. The Open Public Health Journal 5: 36-9. [CrossRef] Ashforth, Blake E., and Glen E. Kreiner. 2002. Normalizing emotion in organizations: Making the extraordinary seem ordinary. Human Resource Management Review 12: 215-35. [CrossRef]

Axelsson, Susanna Bihari, and Runo Axelsson. 2009. From territoriality to altruism in interprofessional collaboration and leadership. Journal of Interprofessional Care 23: 320-30. [CrossRef] [PubMed]

Barr, Victoria J., Sylvia Robinson, Brenda Marin-Link, Lisa Underhill, Anita Dotts, Darlene Ravensdale, and Sandy Salivaras. 2003. The expanded Chronic Care Model: An integration of concepts and strategies from population health promotion and the Chronic Care Model. Healthcare Quarterly 7: 73-82. [CrossRef]

Bhat, Shreeranga, E.V. Gijo, and N.A. Jnanesh. 2014. Application of Lean Six Sigma methodology in the registration process of a hospital. International Journal of Productivity and Performance Management 63: 613-43. [CrossRef]

Bodenheimer, Thomas, and Christine Sinsky. 2014. From Triple to Quadruple Aim: Care of the Patient Requires Care of the Provider. Annals of Family Medicine 12: 573-76. [CrossRef] [PubMed] 
Brotheridge, Céleste M., and Raymond T. Lee. 2008. The emotions of managing: An introduction to the special issue. Journal of Managerial Psychology 23: 108-17. [CrossRef]

Burkitt, Ian. 2014. Emotions and Social Relations. London: Sage.

Cameron, Ailsa, Rachel Lart, Lisa Bostock, and Caroline Coomber. 2014. Factors that promote and hinder joint and integrated working between health and social care services: A review of literature. Health and Social Care in the Community 22: 225-33. [CrossRef] [PubMed]

Diefendorff, James M., Rebecca J. Erickson, Alicia A. Grandey, and Jason J. Dahling. 2011. Emotional Display Rules as Work Unit Norms: A Multilevel Analysis of Emotional Labor among Nurses. Journal of Occupational Health Psychology 16: 170-86. [CrossRef] [PubMed]

D'Amour, Danielle, Lise Goulet, Jean-François Labadie, Leticia San Martín-Rodriguez, and Raynald Pineault. 2008. A Model and typology of collaboration between professionals in healthcare organizations. BMC Health Services Research 8: 188. [CrossRef] [PubMed]

Epstein, Ronald M. 2000. The Science of Patient-Centered Care. Journal of Family Practice 49: 805-10. [PubMed]

Fox, Suzy, and Paul E. Spector. 2002. Emotions in the workplace. The neglected side of organizational life. Introduction. Human Resource Management Review 2: 167-71. [CrossRef]

Garey, Anita Ilta, and Karen V. Hansen. 2011. At the Heart of Work and Family: Engaging the Ideas of Arlie Hochschild. eBook. ProQuest Ebook Central. New Brunswick: Rutgers University Press, Available online: https: / / ebookcentral.proquest.com/lib/uef-ebooks / detail.action?docID=817176 (accessed on 7 October 2018).

Gergen, Kenneth. 1999. An Invitation to Social Construction. London: Sage Publication Ltd.

Goodwin, Nick. 2015. How should integrated care address the challenge of people with complex health and social care needs? Emerging lessons from international case studies. International Journal of Integrated Care 15. [CrossRef]

Greco, Monica, and Paul Stenner, eds. 2008. Emotions, A Social Science Reader. London and New York: Routledge.

Grandey, Alicia A., and Robert C. Melloy. 2017. The state of the heart: Emotional labor as emotion regulation reviewed and revised. Journal of Occupational Health Psychology 22: 407-22. [CrossRef] [PubMed]

Gray, Benjamin. 2009. The emotional labour of nursing-Defining and managing emotions in nursing work. Nurse Education Today 29: 168-75. [CrossRef] [PubMed]

Griffith, Laura, and Jon Glasby. 2015. "When we say 'urgent' it means now ... " Health and social care leaders' perceptions of each other's roles and ways of working. Journal of Integrated Care 23: 143-52. [CrossRef]

Harré, Ron. 1986. The Social Construction of Emotions. Oxford: Basil Blackwell.

Hochschild, Arlie R. 1983. The Managed Heart: Commercialization of Human Feeling. ProQuest Ebook Central. Berkeley, Los Angeles and London: University of California Press, Available online: https: / ebookcentral. proquest.com/lib/uef-ebooks/detail.action?docID=870020 (accessed on 7 October 2018).

Hujala, Anneli, and Johanna Lammintakanen. 2018. Paljon sote-palveluja tarvitsevat asiakkaat keskiöön. Onnistu sote-integraatiossa -tutkimushankkeen raportti. (Clients Needing Multiple Services in the Centre of Integrated Health and Social Care. A Research Project Report). Available online: https://kaks.fi/wpcontent/uploads/2018/01/paljon-sote-palveluja-tarvitsevat-ihmiset-keskioon.pdf (accessed on 14 August 2018). (In Finnish)

Hujala, Anneli, Helena Taskinen, and Sari Rissanen. 2017. How to Support Integration to Promote Care for People with Multimorbidity in Europe? Policy Brief 26, Health Systems and Policy Analysis. Brussels: European Observatory on Health Systems and Policies. Available online: http:/ / www.euro.who.int/en/about-us/partners/observatory/publications / policy-briefs-andsummaries/how-to-support-integration-to-promote-care-for-people-with-multimorbidity-in-europe (accessed on 11 November 2017).

Humphrey, Ronald H., Blake E. Ashforth, and James M. Diefendorff. 2015. The bright side of emotional labor. Journal of Organizational Behavior 36: 749-69. [CrossRef]

Hunter, Billie, and Pam Smith. 2007. Emotional Labour: Just another buzz word. International Journal of Nursing Studies 44: 859-61. [CrossRef] [PubMed]

Jacobsen, Michael H. 2019. Introduction. In Emotions, Everyday Life and Sociology. Edited by Jacobsen Michael H. London and New York: Routledge, pp. 1-12.

Kinman, Gail, and Louise Grant. 2011. Exploring Stress Resilience in Trainee Social Workers: The Role of Emotional and Social Competencies. British Journal of Social Work 41: 261-75. [CrossRef]

Mann, Sandi. 2005. A health-care model of emotional labour. An evaluation of the literature and development of a model. Journal of Health Organization and Management 19: 304-17. [CrossRef] [PubMed] 
Minkman, Mirella. 2016. Values and Principles of Integrated Care. International Journal of Integrated Care 16: 1-3. [CrossRef]

Morrison, Tony. 2007. Emotional Intelligence, Emotion and Social Work: Context, Characteristics, Complications and Contribution. British Journal of Social Work 37: 245-64. [CrossRef]

Oksman, Erja. 2017. Parempi Arki -Hankkeen Loppuraportti. (The Report of the Better Everyday Life Project). Available online: https: / www.innokyla.fi/web/hanke1911098 (accessed on 14 November 2017). (In Finnish)

Osborne, Natalie, and Deanna Grant-Smith. 2015. Supporting mindful planners in a mindless system: Limitations to the emotional turn in planning practice. Town Planning Review 86: 677-98. [CrossRef]

Pratt, Michael G., and Eliana Crosina. 2016. The Nonconscious at Work. Annual Review of Organizational Psychology and Organizational Behavior 3: 321-47. [CrossRef]

Regional Government. 2018. Integration of Social and Health Services. Available online: http:/ /alueuudistus.fi/ en/integration-of-social-and-health-services (accessed on 28 March 2018). (In Finland)

Revell, Lisa, and Victoria Burton. 2016. Supervision and the Dynamics of Collusion: A Rule of Optimism? British Journal of Social Work 46: 1587-601. [CrossRef]

Rijken, Mieke, Verena Struckmann, Iris van der Heide, Anneli Hujala, Francesco Barbabella, Ewout van Ginneken, and François Schellevis. 2017. On Behalf of the ICARE4EU Consortium. In How to Improve Care for People with Multimorbidity in Europe? Policy Brief 23, Health Systems and Policy Analysis. Brussels: European Observatory on Health Systems and Policies. Available online: http://www.euro.who.int/en/about-us/partners/observatory/publications/policybriefs-and-summaries / how-to-improve-care-for-people-with-multimorbidity-in-europe (accessed on 11 November 2017).

Schepman, Sanneke, Johan Hansen, Iris de Putter, Ronald Batenburg, and Dinny de Bakker. 2015. The common characteristics and outcomes of multidisciplinary collaboration in primary health care: A systematic literature review. International Journal of Integrated Care 15: e027. [CrossRef] [PubMed]

Scholl, Isabelle, Jördis M. Zill, Martin Härter, and Jörg Dirmaier. 2014. An Integrative Model of PatientCentredness-A Systematic Review and Concept Analysis. PLoS ONE 9: e107828. [CrossRef] [PubMed]

Schruijer, Sandra. 2008. The Social Psychology of Inter-organizational Relations. In The Oxford Handbook of Inter-Organizational Relations. Edited by Cropper Steve, Huxham Chris, Ebers Mark and Smith Ring Peter. Oxford: Oxford University Press. Available online: http:/ / www.oxfordhandbooks.com/view/10.1093/ oxfordhb/9780199282944.001.0001/oxfordhb-9780199282944-e-16 (accessed on 11 November 2017).

Valentijn, Pim, Sanneke Schepman, Wilfrid Opheij, and Marc Bruijnzeels. 2013. Understanding integrated care: A comprehensive conceptual framework based on the integrative functions of primary care. International Journal of Integrated Care 13: e010. [CrossRef] [PubMed]

Van der Heide, Iris, Sanne Snoeijs, Sabrina Quattrini, Verena Struckmann, Anneli Hujala, Franoois Schellevis, and Mieke Rijken. 2018. Patient-centredness of integrated care programmes for people with multimorbidity. Results from the European ICARE4EU project. Health Policy 122: 36-43. [CrossRef] [PubMed]

World Health Organization. 2016. Framework on Integrated, People-Centered Health Services. Report by the Secretariat. Available online: http://apps.who.int/gb/ebwha/pdf_files/WHA69/A69_39-en.pdf?ua=1 (accessed on 29 March 2018).

Williams, Simon J. 2001. Emotion and Social Theory:Corporeal Reflections on the (Ir) Rational. eBook. ProQuest Ebook Central. London, Thousand Oaks and Calif.: Sage Publications, Available online: https:// ebookcentral. proquest.com/lib/uef-ebooks/detail.action?docID=870020 (accessed on 7 October 2018).

Willumsen, Elisabeth, Bengt Ahgren, and Atle Ødegård. 2012. A conceptual framework for assessing interorganizational integration and interprofessional collaboration. Journal of Interprofessional Care 26: 198-204. [CrossRef] [PubMed]

Zapf, Dieter, and Melanie Holz. 2006. On the positive and negative effects of emotion work in organizations. European Journal of Work and Organizational Psychology 15: 1-28. [CrossRef]

Zapf, Dieter. 2002. Emotion work and psychological well-being. A review of the literature and some conceptual considerations. Human Resource Management Review 12: 237-68. [CrossRef]

(C) 2018 by the authors. Licensee MDPI, Basel, Switzerland. This article is an open access article distributed under the terms and conditions of the Creative Commons Attribution (CC BY) license (http:/ / creativecommons.org/licenses/by/4.0/). 